\title{
Column Liquid Chromatography
}

\author{
Changming Zhang, Zhanggen Huang and Xiaohang Zhang \\ State Key Laboratory of Coal Conversion, \\ Institute of Coal Chemistry, \\ Chinese Academy of Sciences, Taiyuan, \\ China
}

\section{Introduction}

In the processing of coal and petroleum, there are many products produced such as gas and lighter liquid which is easy to use. At the same time, there is heavy material produced which is difficult to use. Such as, in crude oil refine processing, oil thermal cracking and catalytic cracking of petroleum, many residua oils, asphalts, and heaviest "waste" residual will be produced. The quantity of heavy oils is often large. So, it is important to study the property of heavy oils.

The column liquid chromatography (CLC) is an important and indispensable analysis method to study heavy oils. It is not only a separation means, but is also analysis means, especially for analysis of hydrocarbon group type.

Hydrocarbon group type analysis means the determination of the following classes of compounds:

1. Saturated compounds, including paraffinic and naphthenic hydrocarbons.

2. Aromatic compounds, (containing at least one benzene ring). Their molecules containing one benzene ring are classified as mono-aromatics, those with two aromatic rings as di-aromatics, etc.

3. Resins, including polar substances containing elements other than $\mathrm{C}$ and $\mathrm{H}$ in the molecule (nitrogen, sulphur and oxygen in particular)

4. Asphaltenes, including polar substances and asphaltenes only soluble in one or two polar solvents such as quinoline, which have large molecular weight and high aromatic ring number.

Now analysis methods existed have some deficiencies. Such as GC method can not be used to analyze compounds having high boiling point. The application of high performance liquid chromatography (HPLC) to hydrocarbon group-type analysis is characteristic with its high efficiency, high speed, and high sensitivity. But HPLC is only suitable for analysis of substances soluble in $n$-pentane [1].

TLC-FID [2-3] method can be also used to analysis the THF-soluble party in asphalt-samples and show great advantages. But, the components were combusted during TLC-FID analysis 
process and this lack made it not suitable for other analysis with preparation fraction. It should be pointed that the conventional method such as ASTM method use amount of solvent is large and some solvents has high toxicity [4, 5]. Moreover, there are too troublesome for some operation in traditional method. Hence, the separation of products containing heavy components remains a difficult task up to now.

Refereeing the literatures [4-10], the authors of this paper establish an optimum CLC method to analyze group-type of heavy oils through a series of studies. This paper detail introduces this method and its many applications which include preparation of high-level road asphalt, the characterization of molecular weight distributions (MWDs) and analysis of heterocyclic aromatic components of heavy oils.

\section{The establish of CLC method}

\subsection{Column, support and heating apparatus}

The dimension of glass chromatographic column is $90 \mathrm{~mm}$ length and $6 \mathrm{~mm} \mathrm{I}$. D. Silica gel with particle size range from 100 to 200 meshes was provided by marine chemical plant of Qingdao China. Silica gel was active under temperature of $180^{\circ} \mathrm{C}$ for 4 hours before use. Oxide of alumna 0.047-0.147 mm used was purchased from chemical and medical reagent company in Shanghai China. Muffle furnace $\left(50^{\circ} \mathrm{C}-1000^{\circ} \mathrm{C}\right)$ and oven was used for sample preparation and heating.

\subsection{Reagents}

N-heptane, dichloromethane, trichloromethane as eluent solvents all were analytical grade reagents produced by Tianjin Chemical Reagent Factory (China). Pure reagents as model compounds were supplied by Aldrich Chemical Company (USA), including tetracosane (99.5\% pure), dibenz[ah]anthracen ( $98 \%$, pure), and acetanilide ( $99 \%$ pure), etc.

\subsection{Analytical instruments}

Fourier transforms FT-IR spectra were measured by a Bio-Rad Excalibur Series FTS 3000 spectrometer in the range of $4000-400 \mathrm{~cm}^{-1}$ using $\mathrm{KBr}$ pellets. ${ }^{1} \mathrm{H}$ NMR measurements were made with a Bruker Avance 500 spectrometer operating at $500.1 \mathrm{MHz}$.

\section{The establish of group-type analysis method by CLC}

\subsection{Optimum chromatographic condition}

As a base line, some pure reagents were chosen as model components prepared for CLC. These model compounds were tetracosane for saturates, dibenz[ah]anthracen for aromatics and acetanilide for resins. There is no appropriate pure reagent used for asphaltene fraction, so the insoluble fraction of tetrahydrofuran in one asphalt sample was used for asphaltene fraction.

Through a series of investigations, the optimum chromatographic operation was performed. The final optimum conditions were obtained as follows: Chromatographic column was glass column being $90 \mathrm{~mm}$ length, $6 \mathrm{~mm}$ i.d. The amount of silica gel used was from 1 to 1.5 gram. 
The amount of alumina was from 1.5 to 1.8 gram. Total sample used was about 0.1 gram. The solvent of heptanes, mixture of heptanes/ dichloromethane $(1 / 2.5, \mathrm{~V} / \mathrm{V})$ and mixture of dichloromethane/ trichloromethane $(1 / 3, \mathrm{~V} / \mathrm{V})$ were as elutes corresponding to saturated hydrocarbon, aromatic hydrocarbon and resin respectively. The amount of heptanes, heptanes/ dichloromethane, and dichloromethane/ trichloromethane was $20 \mathrm{ml}, 35 \mathrm{ml}$ and $30 \mathrm{ml}$ respectively. Each fraction collected was dried in vacuum under $60^{\circ} \mathrm{C}$ until the weight keep constant.

Through above group analysis, the experimental deviation and recovery of CLC method are summarized in Table 1. From Table, it can be seen that the average of deviation and recover are $-1.546 \%$ and $100.681 \%$ respectively; the results are good.

\begin{tabular}{|c|c|c|c|c|c|c|}
\hline $\begin{array}{c}\text { Pure } \\
\text { Reagents }\end{array}$ & $\begin{array}{c}\text { Weight of } \\
\text { preparation }\end{array}$ & $\begin{array}{c}\text { Content } \\
\text { W\% }\end{array}$ & $\begin{array}{c}\text { Determination } \\
\text { W\% }\end{array}$ & $\begin{array}{c}\text { Deviation } \\
\text { W\% }\end{array}$ & $\begin{array}{c}\text { Recover } \\
\%\end{array}$ & No. \\
\hline Tetracosane & $0.0547(\mathrm{~g})$ & 100 & 98.095 & -1.905 & 98.095 & 1017 \\
\hline Tetracosane & 0.0508 & 100 & 97.964 & -2.036 & 97.964 & 1020 \\
\hline Tetracosane & 0.0311 & 27.154 & 26.658 & -0.496 & 98.173 & 1201 \\
\hline Tetracosane & 0.0285 & 26.571 & 25.638 & -0.933 & 96.489 & 1202 \\
\hline Average & & & & -1.343 & 97.680 & \\
\hline Dibenz(ah)anthracen & 0.042 & 100 & 98.095 & -1.805 & 98.095 & 1030 \\
\hline Dibenz(ah)anthracen & 0.0442 & 100 & 97.964 & -2.036 & 97.964 & 1103 \\
\hline Dibenz(ah)anthracen & 0.0259 & 22.629 & 20.909 & -1.720 & 92.399 & 1201 \\
\hline Dibenz(ah)anthracen & 0.0294 & 27.402 & 26.843 & -0.559 & 97.960 & 1202 \\
\hline Average & & & & -1.530 & 96.605 & \\
\hline Acetanilide & 0.0875 & 100 & 97.600 & -2.400 & 97.600 & 1024 \\
\hline Acetanilide & 0.0247 & 23.024 & 22.642 & -0.382 & 98.341 & 1202 \\
\hline Acetanilide & 0.0365 & 100 & 96.438 & -3.562 & 96.438 & 1222 \\
\hline Acetanilide & & 27.402 & 26.843 & -0.559 & 97.853 & 1201 \\
\hline Average & & & & -1.726 & 97.558 & \\
\hline Asphltene & 0.0261 & 22.815 & 24.790 & 1.975 & 108.657 & 1201 \\
\hline Asphltene & 0.0395 & 100 & 94.937 & -5.063 & 94.937 & 1211 \\
\hline Asphltene & 0.0387 & 100 & 98.450 & -1.550 & 98.450 & 1301 \\
\hline Average & & & & -1.546 & 100.681 & \\
\hline
\end{tabular}

Table 1. Experimental deviation and recovery of model compound.

\subsection{Check of chromatographic resolution rate by FT-IR}

The result of CLC method was checked by Fourier transform infrared (FT-IR) method .The spectra IR were acquired in the transmission mode as 64 scan in the IR range from 4000 to $500 \mathrm{~cm}^{-1}$ at a resolution of $4 \mathrm{~cm}^{-1} . \mathrm{KBr}$ standard pellets were used, and the samples were dried and then mixed with $\mathrm{KBr}$, ground, and palletized.

IR spectrums of pure reagents including tetracosane, dibenz(ah)anthracen and acetanilide were obtained and used for standards. The IR spectrums of different fractions collected from flow out separated of the mixture reagents, and spectrums were compared with above standard spectrums. The results were shown in Figure 1. 


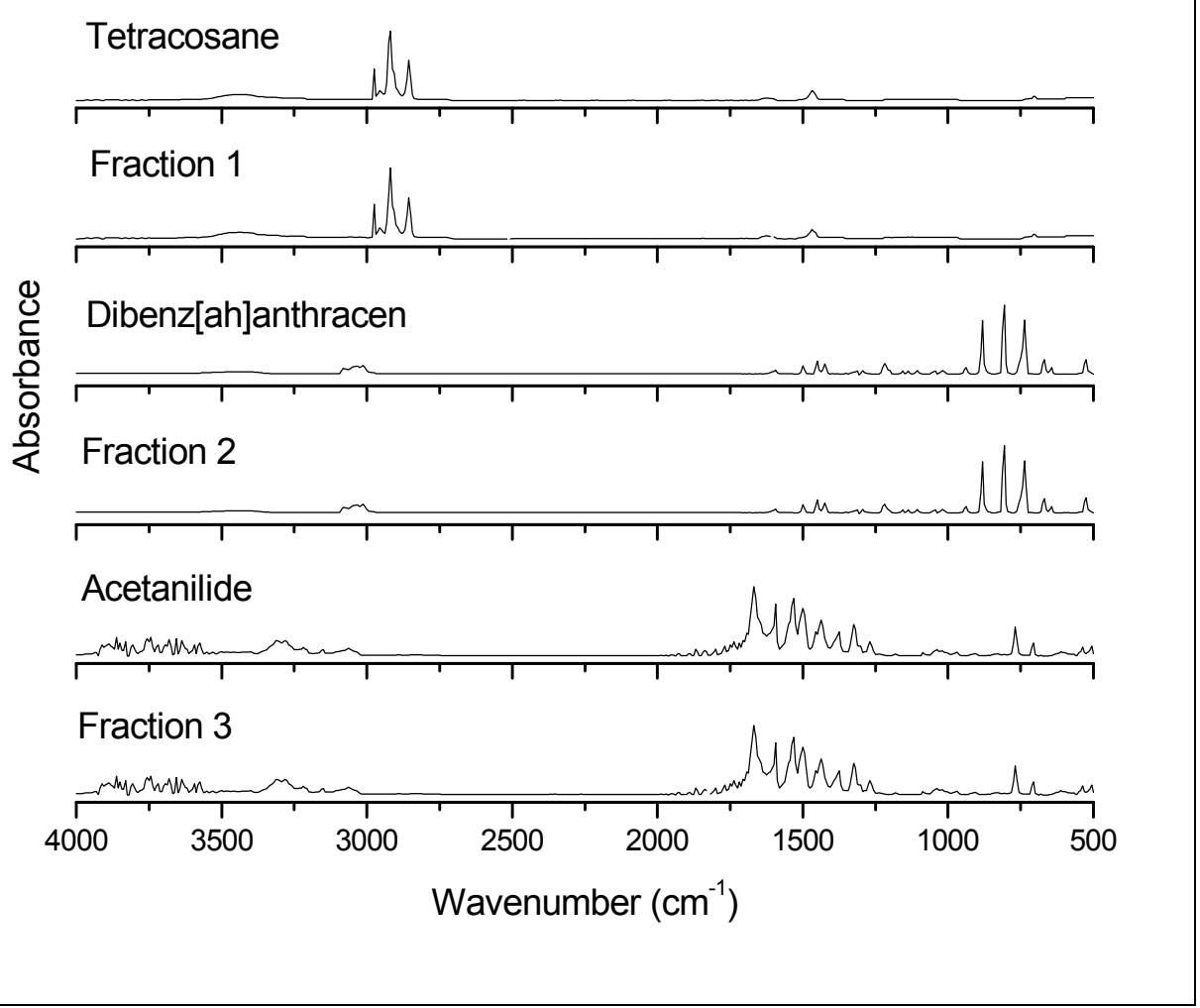

Fig. 1. Infrared spectrum for pure reagents and different fraction.

It is important to indicate that the IR spectra of fraction 1 collected (from 1202\# sample) show similarity with pure tetracosane reagent. IR spectra for fraction 2 and fraction 3 show accordant results with dibenz(ah)anthracen and acetanilide respectively.

\subsection{Check of chromatographic resolution rate by ${ }^{1} \mathrm{H}$ NMR}

The CLC method was checked also by ${ }^{1} \mathrm{H}$ NMR. It measured different fractions collected from flow out separated of the mixture reagents and spectrums were compared with above standard spectrums. The high resolution ${ }^{1} \mathrm{H}$ NMR spectra of pure model compounds and fraction 1-3 are shown in Figure 2.

It is difficult to separate complex and heavy sample, however the IR and ${ }^{1} \mathrm{H}$ NMR analysis of the prepared fractions from CLC were all good agreement with pure reagents. This observation indicate the optimum CLC parameter in this work guarantee a good qualitative results. 


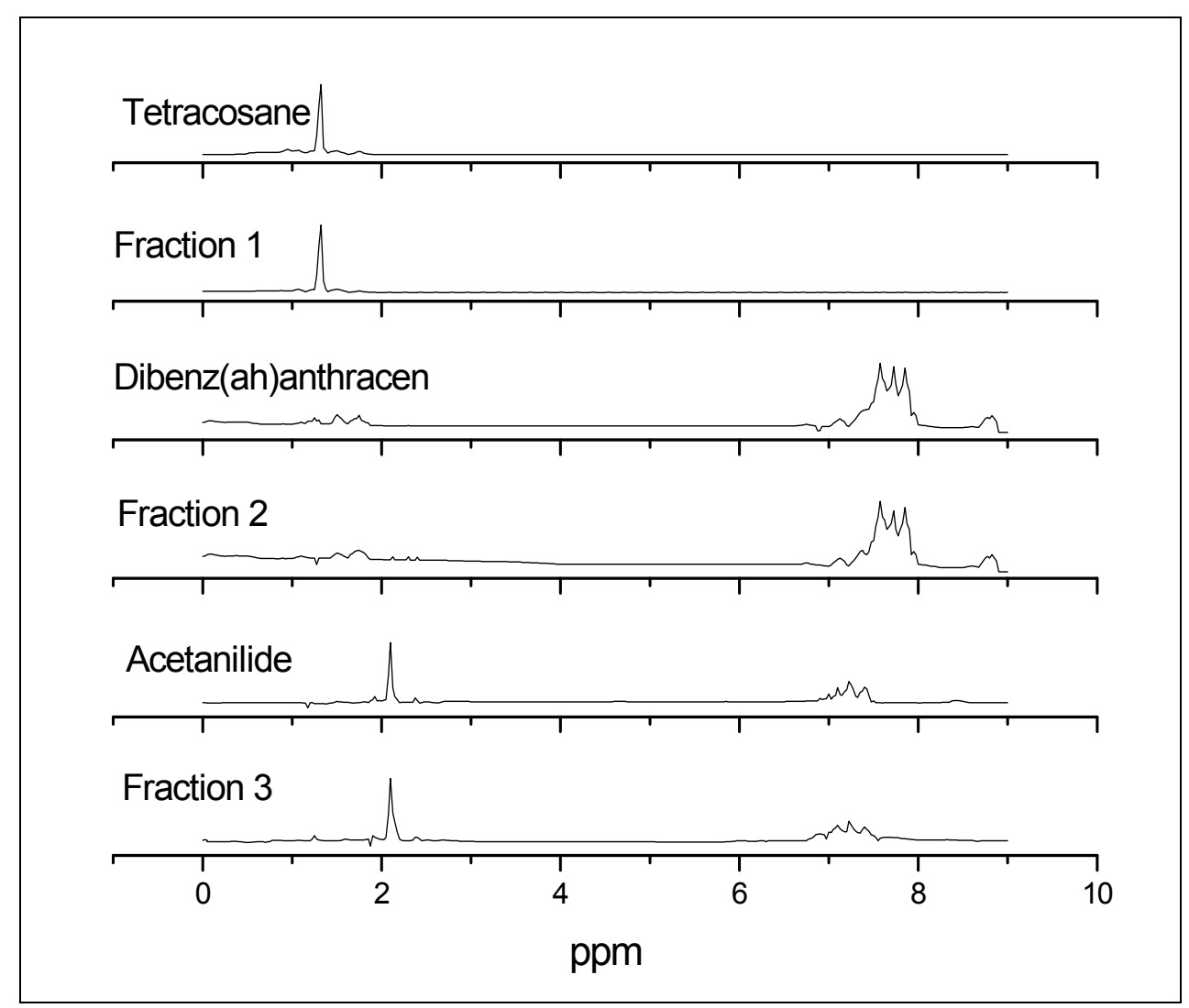

Fig. 2. ${ }^{1} \mathrm{H}$ NMR results of pure reagents and different fraction.

\subsection{Evaluation of analysis of group composition by CLC}

The recover rate and experiment deviations for model compounds were summarized in Table 1. It can be seen that the experiment result are fine.

Compared with routine ASTM method, these optimum chromatographic conditions show many advantages. First, the reagent and sample consumed was fewer than total solvent of $300 \mathrm{ml}$ of classic ASTM method. Second, the dichloromethane and trichloromethane used in present study, compared with toluene and benzotrichloride used, has lower toxicity.

\section{Applications of group type analysis by CLC}

\subsection{The application in making high grade road asphalt}

Coal is used as the main source of energy in China. The crude oil produced in China is paraffinic; therefore, it is not suitable for road asphalt. China is trying to produce high grade road asphalt from the mixture of coal and petroleum $[11,12]$. 
Three asphalt samples from petroleum and coal processing for high grade paving asphalt were characterized by established method. Sample NE-6, NE-9, NE-11 were the heavy products by co-processing of Shijiazhuang oil (a petroleum factory in China) and Yanzhou coal (a typical coal in China). The coal and oil ratio was 1:1. Among asphalt samples, the preparation of NE-6 sample was under the role of Fe catalyst during co-processing. NE-9 sample was related to Mo catalyst. The sample TLA is from Trindid Lake Asphalt. The results of group type analysis for four asphalt samples were shown in Table 2.

\begin{tabular}{cccccc}
\hline Name & Test & Saturates & Aromatics & Resins & Asphaltenes \\
\hline NE-6 & $(1)$ & 5.496 & 60.154 & 17.327 & 17.023 \\
& $(2)$ & 4.986 & 58.230 & 20.128 & 15.855 \\
& Average & 5.241 & 59.191 & 18.727 & 16.439 \\
& Deviation & 0.255 & 0.961 & 1.401 & 0.584 \\
NE-9 & $(1)$ & 9.950 & 21.379 & 52.906 & 15.765 \\
& $(2)$ & 8.001 & 22.087 & 52.348 & 17.554 \\
& Average & 8.975 & 21.733 & 52.627 & 16.659 \\
& Deviation & 0.974 & 0.354 & 0.279 & 0.895 \\
NE-11 & $(1)$ & 7.375 & 66.379 & 23.659 & 2.586 \\
& $(2)$ & 8.497 & 67.984 & 20.850 & 2.668 \\
& Average & 7.936 & 67.182 & 22.254 & 2.627 \\
& Deviation & 0.561 & 0.802 & 1.404 & 0.041 \\
TLA & $(1)$ & 5.496 & 60.154 & 17.327 & 17.023 \\
& $(2)$ & 4.986 & 58.230 & 20.928 & 15.855 \\
& Average & 5.241 & 59.191 & 19.128 & 16.439 \\
& Deviation & 0.255 & 0.961 & 1.800 & 0.584 \\
\hline
\end{tabular}

Table 2. Results of groups composition of asphalts (W\%).

From Table 2 it can be seen that the application of established method to real asphalt samples show good results. Different samples have different group composition characterize. The experiment deviations of contents $(\mathrm{W} \%)$ are in the ranges from $0.255 \%$ to $1.800 \%$.

FTIR experiments were performed to check the qualitative ability of established method. IR spectra of saturated fraction, aromatic fraction and resin fraction for sample NE-9 were shown in Figure from 3 to 5. It is important to note intense absorption peaks for saturated fraction (Fig.3). Based the standard IR handbook, the absorption peaks around $719.45 \mathrm{~cm}^{-1}$, $1377.17 \mathrm{~cm}^{-1}, 2850.78 \mathrm{~cm}^{-1}, 2918.29 \mathrm{~cm}^{-1}$ and $2959.79 \mathrm{~cm}^{-1}$ was attributed to characteristics peak for $\delta\left(\mathrm{CH}_{2}\right)_{\mathrm{N}} \mathrm{N}>6, \delta\left(\mathrm{CH}_{3}\right), v_{s} \mathrm{CH}_{3}, v_{\text {as }}\left(\mathrm{CH}_{2}\right)$ and $v_{\text {as }} \mathrm{CH}_{3}$ respectively. These data show that the prepared saturated fraction has a high purity.

As Figure 4 show, the absorption peaks around $748.38 \mathrm{~cm}^{-1}, 812.03 \mathrm{~cm}^{-1}, 877.61 \mathrm{~cm}^{-1}$ and $3049.45 \mathrm{~cm}^{-1}$ belong to character peak of aromatic C-H absorption. The peaks at $1602.84 \mathrm{~cm}^{-}$ $1,1580 \mathrm{~cm}^{-1}$ and $1410 \mathrm{~cm}^{-1}$ were characteristics absorption peak of aromatic carbon. Obviously, the obtained aromatic hydrocarbon fraction has a good purity. 


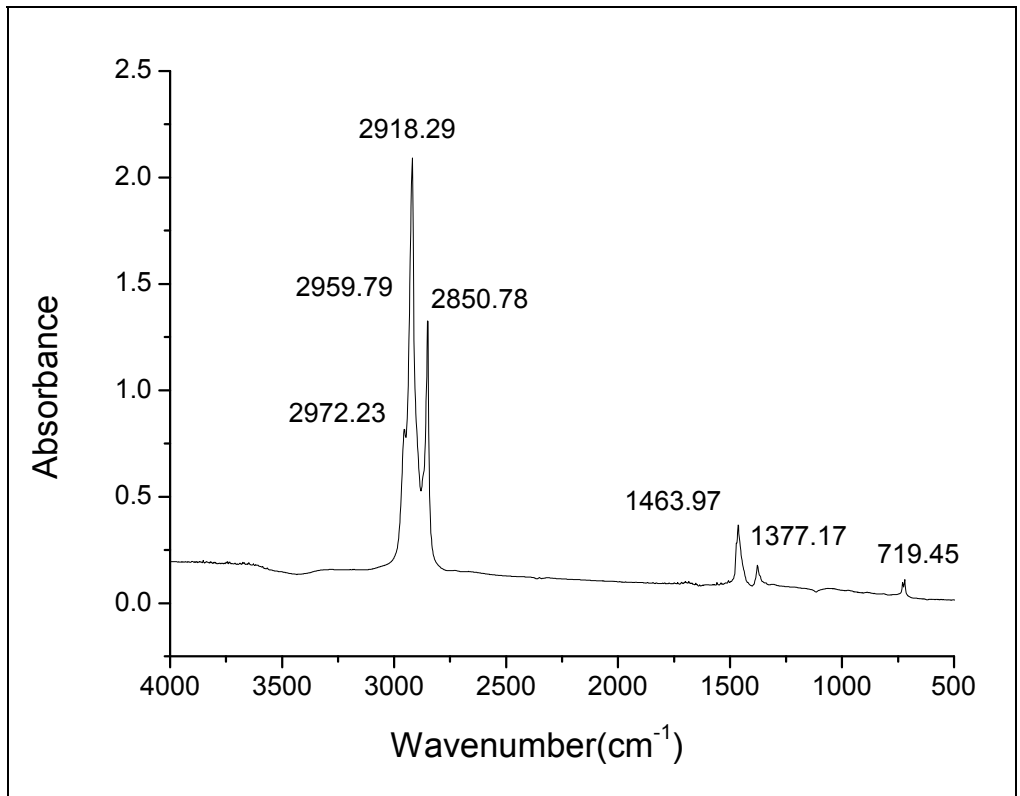

Fig. 3. Infrared spectrum of the saturated hydrocarbon fraction of sample NE-9.

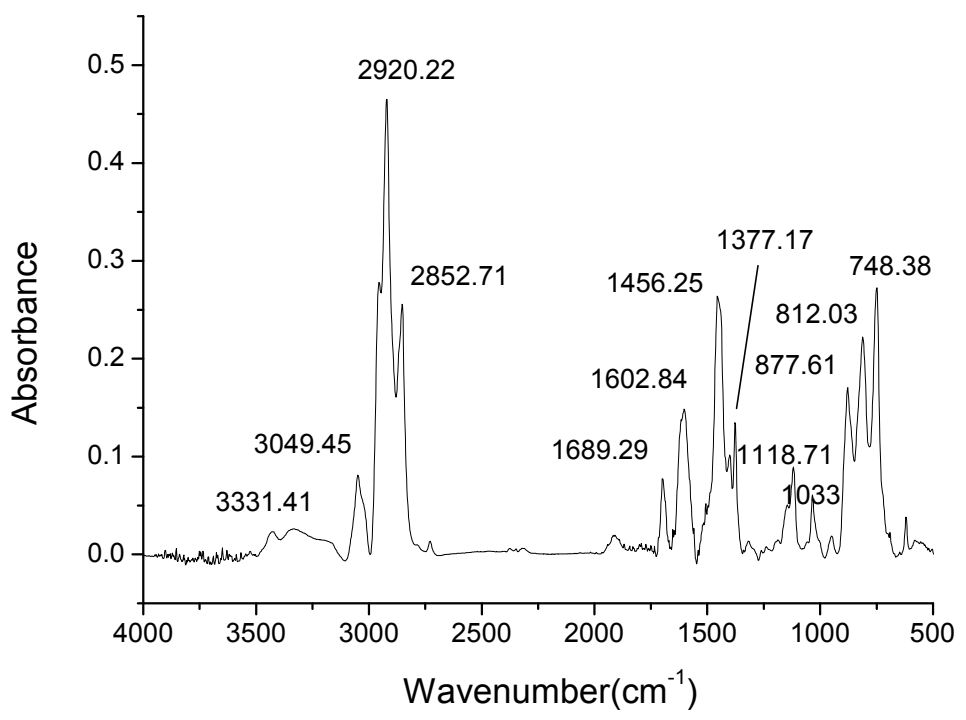

Fig. 4. Infrared spectrum of the aromatic fraction of sample NE-9.

The results from Figure 5 show that the resin fractions concentrate some oxygen-containing compounds. This conclusion can be approved by the appearing peak around $1215.15 \mathrm{~cm}-1$, which is characteristics absorption peak for phenol compounds, and peak around 3649.31 
$\mathrm{cm}-1$, which is characteristics absorption peak for dissociate $\mathrm{OH}$. The peaks at $1033.84 \mathrm{~cm}-1$ and $1608.63 \mathrm{~cm}-1$ attribute to the absorption from $\mathrm{OH}$ and $\mathrm{C}-\mathrm{O}-\mathrm{C}$ group. This is comprehensible because $\mathrm{OH}$ group in the structure the phenol connects to the aryl group, which may induce some aromatic absorption peaks.

The FTIR results show high resolution of CLC method established. It is difficult to separate complex and heavy sample, however the IR analysis of the prepared fractions from the CLC chow all good results This observation indicate that chromatographic parameter guarantee a good qualitative results.

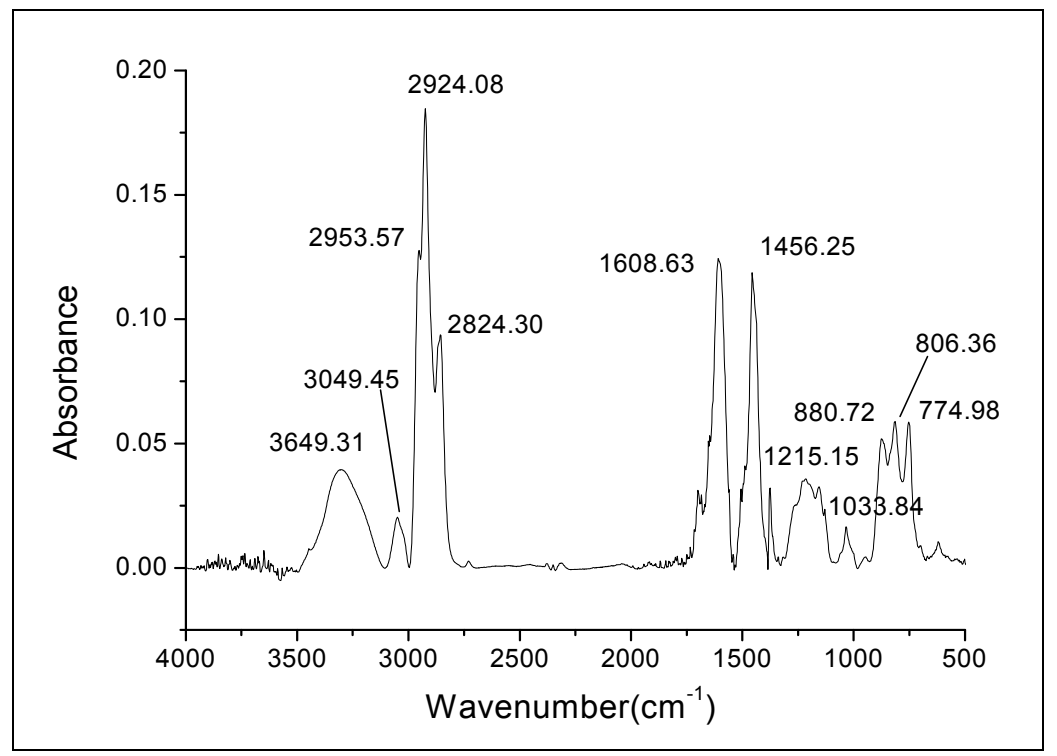

Fig. 5. Infrared spectrum of the resin fraction of sample NE-9.

\subsection{The determination of MWDs by CLC coupled with SEC}

Among characteristics of heavy oil, the size exchange chromatography (SEC) can be used to determine molecular weight distributions (MWDs), weight average molecular weight (Mw) and number average molecular weight $(\mathrm{Mn})$, etc. With heavy oil of a group as example, the conditions of SEC are summarized as follows.

The analysis conditions are: a Shimadzu LC-10A high performance liquid chromatograph with an SPD-10AUP UV detector, the chromatographic column of SHIMPACK $-801(30 \mathrm{~cm}$ length, $0.8 \mathrm{~cm}$ i.d., polystyrene $6 \mu \mathrm{m}$ ), mobile phase of THF; flow rat with $1.2 \mathrm{ml} / \mathrm{min}$; column temperature at $25^{\circ} \mathrm{C}$.

The SEC chromatograms are shown in Figure 6, MWDs results are listed in Table 3.

In Figure 6, the sources of coal asphalt, KP petroleum asphalt, ethylene residue oil and vacuum residue oil are from Shanxi coking plant in China, Korea refining, Xinjiang oil refinery in China and Saudi Arabia's oil refining, respectively. 


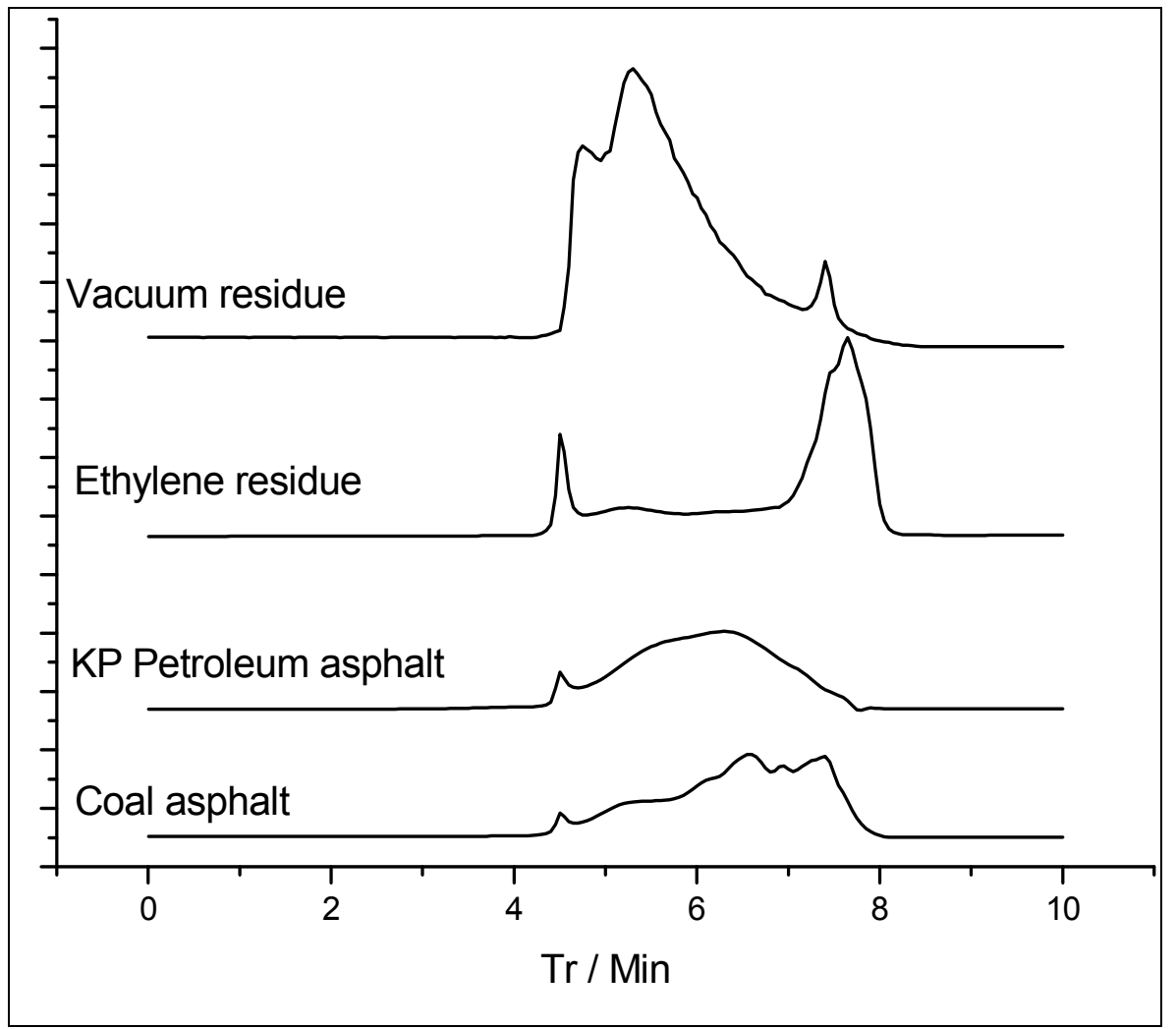

Fig. 6. The SEC chromatograms of typical heavy oils.

\begin{tabular}{|c|c|c|c|c|c|c|c|}
\hline \multirow[b]{2}{*}{ Samples } & \multirow[b]{2}{*}{ Mw } & \multicolumn{6}{|c|}{ W\% } \\
\hline & & $M>5000$ & $\begin{array}{l}\text { M5000 } \\
-3000\end{array}$ & $\begin{array}{c}\text { M3000 } \\
-1000\end{array}$ & $\begin{array}{l}\text { M1000 } \\
-500\end{array}$ & $\begin{array}{c}\text { M500 } \\
-300\end{array}$ & $M<300$ \\
\hline Coal asphalt & 1032.200 & 1.658 & 2.802 & 21.199 & 29.730 & 22.745 & 21.863 \\
\hline $\begin{array}{l}\text { KP Petroleum } \\
\text { asphalt }\end{array}$ & 1905.674 & 0.804 & 17.169 & 59.899 & 12.274 & 3.979 & 5.873 \\
\hline $\begin{array}{c}\text { "Ethylene" residue } \\
\text { oil }\end{array}$ & 764.788 & 0.191 & 7.481 & 15.201 & 9.648 & 9.666 & 57.810 \\
\hline Vacuum residue oil & 1886.698 & 3.683 & 1.490 & 61.166 & 20.566 & 6.399 & 6.693 \\
\hline
\end{tabular}

Table 3. The MWDs of typical heavy oils

How much is the "representative" characteristics of this SEC method? This is an important problem to need know to treating these spectra and data of SEC. The so-called "representative" refers that extent which could be determined out of sample. Because most present SEC method is only suitable to compounds having UV adsorbent and soluble of THF, so, it is needed to know representative of whole sample. This problem will be completed only by CLC. Because the four groups: saturates, aromatics, resins and 
asphaltenes quantitatively could be obtained by CLC determination, then the "representative "( $\mathrm{R}$ index) will be calculated as the following.

$$
\mathrm{R}=100 \%-\mathrm{W}_{\mathrm{asp}} \%-\mathrm{W}_{\mathrm{a} 1 \mathrm{k}} \%
$$

Which $\mathrm{R}$ represents the representation index; $\mathrm{W}_{\mathrm{asph}} \%$ and $\mathrm{W}_{\mathrm{a} 1 \mathrm{k}} \%$ represent the weight percent of asphaltene in sample and the weight percent of saturated hydrocarbons in sample, respectively.

With samples of Figure 6 as example, their R indexes from this CLC analysis are listed in Table 4.

\begin{tabular}{cccccc}
\hline Name of samples & $(1)$ & $(2)$ & $(3)$ & Average & Max of deviation \% \\
\hline Coal asphalt & 73.64 & 72.89 & 73.86 & 73.46 & -0.78 \\
KP petroleum asphalt, & 99.33 & 99.28 & 98.76 & 99.12 & -0.36 \\
Ethylene residue oil & 90.36 & 89.87 & 90.56 & 90.26 & -0.43 \\
Vacuum residue oil & 96.17 & 96.21 & 95.76 & 96.05 & 0.33 \\
\hline
\end{tabular}

Table 4. The R indicators.

These results show that the CLC coupled with SEC is an effective mean to analyze MWDs.

\subsection{Analysis of resin component by CLC coupled with HPLC}

As components of resin of heavy oil are very complicated, so to analyze them is very difficult by only one method. However, CLC coupled with high performance liquid chromatography (HPLC) can separate successfully, quality and quantity these compositions. Because the resin fraction got concentrate oxygen-containing compounds and other heteroatom-containing compounds by CLC separation, then the analysis of these hetero-atomcontaining compounds became easy to by HPLC. With slurry oil (Tianjing Refinery of China) as an example, the analysis of components in resin was summarized as follows.

The preparation of resin fraction was same as that of above description of CLC; the HPLC was performed on a Shimadzu LC-3A chromatogram with a SPD-1 UV detector, operated at $254 \mathrm{~nm}$. Two ODS $(4.6 \times 20 \mathrm{~cm})$ columns in series were operated at $40{ }^{\circ} \mathrm{C}$ with methanol / water $=78: 22(\mathrm{~V} / \mathrm{V})$ as the mobile phase, flowing at a rate of $0.8 \mathrm{ml} / \mathrm{min}$. Typical separation chromatogram is shown in Figure 7.

From Figure 7 it can be seen the high resolution separation rate of complex compositions, these confirmed that the CLC preparation is successful and HPLC analysis is better.

The three qualitative methods of HPLC were selected to determine compositions of resin fraction. The three methods [13] are follows.

1. The qualitative method of relative retention time (RRT).

2. The qualitative method of stop- flow UV scanning.

3. The qualitative method of UV characteristic index $\mathrm{V}^{\prime}$.

The quantitative determination of compositions was by the method of external standard (E$\mathrm{X})$ and the calculation formula uses the following.

$$
\mathrm{W}_{\mathrm{x}} \%=\left(\mathrm{R}_{\mathrm{ex}} / \mathrm{C}_{\mathrm{x}}\right) *\left(\mathrm{~S}_{\mathrm{x}} / \mathrm{S}_{\mathrm{ex}}\right) *\left(\mathrm{~V}_{\mathrm{ex}} / \mathrm{V}_{\mathrm{x}}\right) * \mathrm{R}_{\mathrm{es}} \%
$$


where $\mathrm{W}_{\mathrm{x}} \%$ is the weight content percent of $\mathrm{x}$ composition in heavy oil sample, $\mathrm{R}_{\mathrm{x}} \%$ and $\mathrm{C}_{\mathrm{ex}} \%$ are the concentration of preparation solution of resin fraction and external standard solution, respectively, $S_{x}$ and $S_{e x}$ are the peak areas of component $x$ and external standard, respectively, $V_{\text {ex }}$ and $V_{x}$ are the injection volumes of external standard solution and resin solution, respectively, $\mathrm{R}_{\mathrm{es}} \%$ is the weight percent of resin fraction in heavy oil sample. The qualitative and quantitative results are in Table 5.

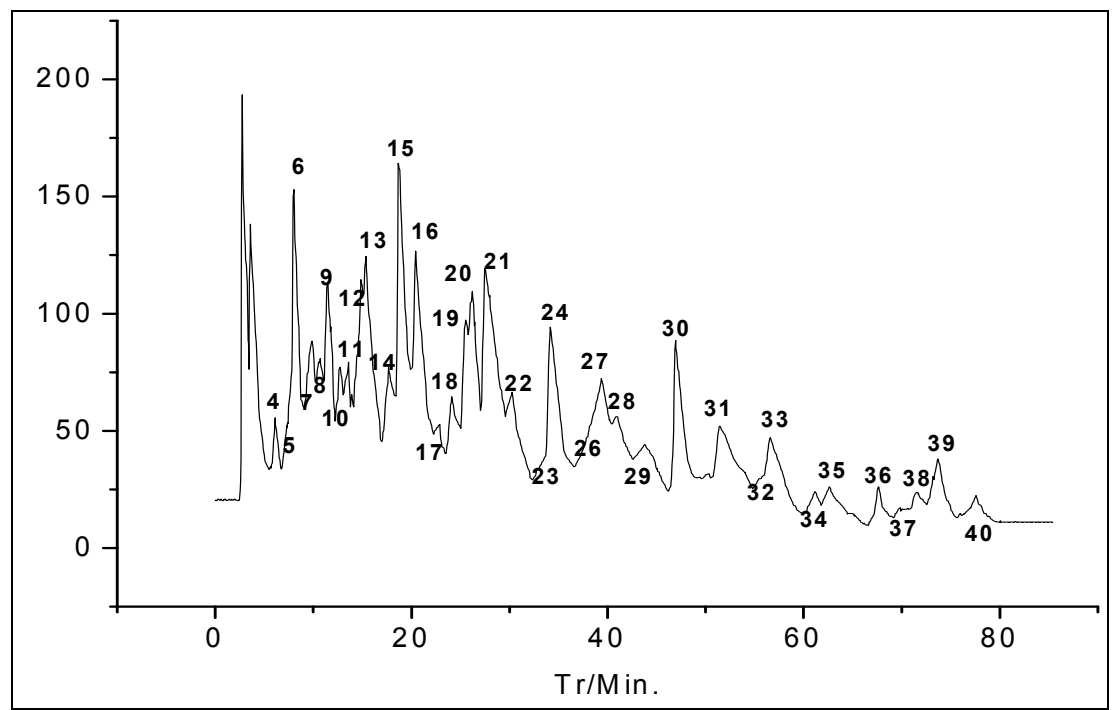

Fig. 7. HPLC chromatogram of resin fraction.

\begin{tabular}{|c|c|c|c|c|c|}
\hline $\begin{array}{c}\text { Number } \\
\text { of peak }\end{array}$ & Component & $\begin{array}{c}\text { Quantitative } \\
\text { results }\end{array}$ & $\begin{array}{c}\text { Number } \\
\text { of peak }\end{array}$ & Component & $\begin{array}{c}\text { Quantitative } \\
\text { results (ppm) }\end{array}$ \\
\hline 9 & 3-Methyl indole & 610 & 15 & N-phenyl pyrrole & 800 \\
\hline 10 & Quinoline & 240 & 16 & 7,8 -Benzoquinoline & 1000 \\
\hline 11 & $\begin{array}{c}\text { Phenanthrene- } \\
\text { quinone }\end{array}$ & 240 & 18 & p-phenyl phenol & 500 \\
\hline 12 & Carbazole & 500 & 20 & N-phenyl indole & 600 \\
\hline 13 & 4-Methylquinoline & 640 & 24 & Dibenzofuran & 630 \\
\hline 14 & 2-Amino-phenol & 570 & 33 & N-Ethyl carbozole & 370 \\
\hline Note & & ppm & 35 & 2,2'-Biquinoline & 290 \\
\hline
\end{tabular}

Table 5. Results of components of resin (ppm).

\section{Conclusion}

A modified method for group type analysis of asphalt using CLC was established. The small-type CLC technique shows many advantages, such as high resolution rate, rapid operation, and requires minimal quantities of sample and solvent. The both of IR and ${ }^{1} \mathrm{H}$ NMR results check the high resolution of this method. 
The CLC method compared with routine ASTM method, the reagents used in this method are small amount and lower toxicity. These are beneficial to environmental protection and human health. This is very important for modern analysis.

The CLC method of this paper is an important and indispensable analysis method to study heavy oils. It is not only a separation means, but is also analysis means. This method was successfully applied to many analysis aspects, such as making high grade road asphalt, characterizing MWDs and analysis heterocyclic of aromatic compositions of heavy oils.

The analysis of heavy oil is a long and difficult task. We systematically summarized these studies and hope that these will help our colleagues.

\section{References}

[1] Changming Zhang, Aiying Li, Yongii Li, Zengmin Sen. Analysis of the class composition of some residual oils and asphalts by HPLC. Preprints, Division of petroleum chemistry[C].INC. American Chemical Society, 1989, 34(2):240-246.

[2] Zhe Wang, Changming Zhang. A study on the relationship between the composition and the usage of asphaltic heavy oil. Preprints, Division of petroleum chemistry[C].INC. American Chemical Society, 1992, 37(3):933-936.

[3] Zhang Changming, Li Aiying, Li Ying, Zhang linmei. Instrumental analysis and systematic investigation on heavy oils from coal. Chinese journal of Chromatography, 1999, 17(4):372-375.

[4] Copyright by the ASTM international. Standard test method for separation of asphalt into four fractions. 2002, Thu Dec 05 15; 56; 14.

[5] Shu-an Qian, Peng-zhou Zhang, Bai-ling Li, Structural characterization of pitch feedstocks for coke making. Fuel, 1995, 64(8): 1085-1091.

[6] Standard of geologic office of the People's Republic of China, Analytical method of class composition for crude oil and extract organic,1987,05-23.

[7] Justin D, Fair, Chad M.Kormos, Flash column chromatograms estimated from thin-layer chromatography data. Journal of Chromatography A, 2008, 1211:49-54.

[8] Davies, Don R., Johnson, Todd M. Isolation of three components from spearmint oil: An exercise in column and thin-layer chromatography. J. Chem. Educ. 2007,84(2):318-320.

[9] B. Concho-Grande, M. Rodriguez-Comesafia, J.Simal-Gandara, Sample HPLC determination of colistin in modicated feeds by pre-column derivatization and fluorescence detection. Chromatographia , 2001,54(7/8):481-484.

[10] B Liawruangrath, S. Liawruangrath, High performance thin layer chromatographic determination of erythromycin in pharmaceutical preparation. Chromatographia, 2001,54(5/6):405-408.

[11] Yongbing Xue, Jianli Yang, Zhenyu Liu, Zhiyu Wang, Zengnou Liu,Yunmei Li,Yuzhen Zhang, Paving asphalt modifier from co-processing of FCC slurry with coal. Catalysis Today 2004,98:333-338.

[12] Aroon Shenoy, Prediction of high temperature rheological properties of aged asphalts from the flow data of the original unaged samples. Construction and Building Materials, 2002,16 (8):509-517.

[13] Changming Zhang, Xiaohang Zhang, Jianli Yang, Zhenyu Liu, Analysis of polynuclear aromatic hydrocarbons in heavy ducts derived from coal and petroleum by high performance liquid chromatography. J. chromatogr. A, 2007, 167, 171-177. 


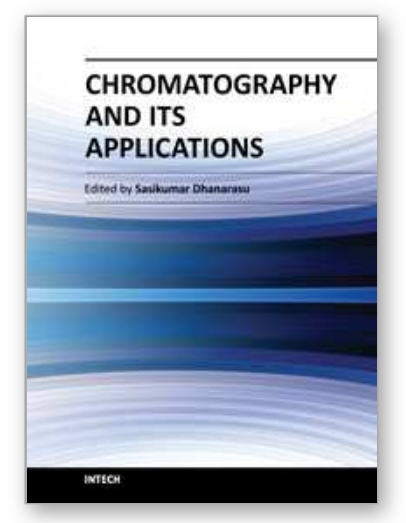

\author{
Chromatography and Its Applications \\ Edited by Dr. Sasikumar Dhanarasu
}

ISBN 978-953-51-0357-8

Hard cover, 224 pages

Publisher InTech

Published online 16, March, 2012

Published in print edition March, 2012

Chromatography is a powerful separation tool that is used in all branches of science, and is often the only means of separating components from complex mixtures. The Russian botanist Mikhail Tswett coined the term chromatography in 1906. The first analytical use of chromatography was described by James and Martin in 1952 , for the use of gas chromatography for the analysis of fatty acid mixtures. A wide range of chromatographic procedures makes use of differences in size, binding affinities, charge, and other properties. Many types of chromatography have been developed. These include Column chromatography, High performance liquid chromatography (HPLC), Gas chromatography, Size exclusion chromatography, Ion exchange chromatography etc. In this book contains more details about the applications of chromatography by various research findings. Each and every topics of this book have included lists of references at the end to provide students and researchers with starting points for independent chromatography explorations. I welcome comments, criticisms, and suggestions from students, faculty and researchers.

\title{
How to reference
}

In order to correctly reference this scholarly work, feel free to copy and paste the following:

Changming Zhang, Zhanggen Huang and Xiaohang Zhang (2012). Column Liquid Chromatography, Chromatography and Its Applications, Dr. Sasikumar Dhanarasu (Ed.), ISBN: 978-953-51-0357-8, InTech, Available from: http://www.intechopen.com/books/chromatography-and-its-applications/the-column-liquidchromatography-and-its-applications

\section{INTECH}

open science | open minds

\section{InTech Europe}

University Campus STeP Ri

Slavka Krautzeka 83/A

51000 Rijeka, Croatia

Phone: +385 (51) 770447

Fax: +385 (51) 686166

www.intechopen.com

\section{InTech China}

Unit 405, Office Block, Hotel Equatorial Shanghai

No.65, Yan An Road (West), Shanghai, 200040, China

中国上海市延安西路 65 号上海国际贵都大饭店办公楼 405 单元

Phone: +86-21-62489820

Fax: $+86-21-62489821$ 
(C) 2012 The Author(s). Licensee IntechOpen. This is an open access article distributed under the terms of the Creative Commons Attribution 3.0 License, which permits unrestricted use, distribution, and reproduction in any medium, provided the original work is properly cited. 